\title{
Tricuspid valve-in-valve procedure: a step-by-step guideline
}

\author{
Valve-in-valve tricúspide una guía paso a paso \\ Julieta D. Morales-Portano ${ }^{1}$, Roberto Muratalla-González ${ }^{1}$, José L. Zaldivar-Fujigaki², \\ Vania I. Díaz-Plaza1', Elsa Rojas-Hernández ${ }^{3}$, Abril A. Gutiérrez-Balcazar ${ }^{3}$ and José A. Merino-Rajme ${ }^{1 *}$ \\ ${ }^{1}$ Department of Cardiology; ${ }^{2}$ Clinical Research; ${ }^{3}$ Department of Echocardiography, National Medical Center, 20 de Noviembre ISSSTE, Mexico City, \\ Mexico
}

\begin{abstract}
Objective: The aim of this study was to present a valve-in-valve (ViV) case and a step-by-step guideline on how to perform this procedure. Methods: A 51-year-old female with a history of rheumatic heart disease and tricuspid valve replacement presented functional class deterioration, a transesophageal echocardiogram (TEE) revealed prosthetic dysfunction due to thrombosis; therefore, a valvular replacement with a $27 \mathrm{~mm}$ bioprosthesis (Carpentier-Edwards Perimount) was performed without complication. 3 years after the procedure, the patients presented functional class deterioration (NYHA-III) with tricuspid dysfunction by TEE and the heart team decided to perform a transcatheter tricuspid ViV replacement.
\end{abstract}

Key words: Valve-in-valve. Tricuspid replacement. Step-by-step guideline. Mexico.

\section{Resumen}

Objetivo: El objetivo de este artículo es presentar un caso clínico de un paciente en el cual se realizó el procedimiento valve-in-valve (ViV) en la válvula tricúspide junto con una guía de cómo llevar a cabo este procedimiento paso a paso. Metodología: Paciente femenino de 51 años de edad con antecedente de Cardiopatía Reumática presenta deterioro en clase funcional encontrándose por ecocardiografía transesofágica (ETE) disfunción de válvula protésica tricúspide secundario a trombosis, se realiza recambio valvular con prótesis biológica $27 \mathrm{~mm}$ (Carpentier Edwards Perimount) sin complicación. 3 años después, presenta deterioro de la clase funcional (NYHA-III) y se evidencia en ETE disfunción protésica tricúspide por lo cual se decide realizar un reemplazo ViV tricúspide transcatéter.

Palabras clave: Valve-in-valve. Remplazo tricúspide. Guía paso a paso. México.

\section{Correspondence:}

*José Alfredo Merino-Rajme

E-mail: alfredo.merino@issste.gob.mx

1405-9940 @ 2019 Instituto Nacional de Cardiología Ignacio Chávez. Publicado por Pern 1405-9940 ( 2019 Instituto Nacional de Cardiología Ignacio Chávez. Publicado por Permanyer México SA de CV. Este es un artículo Open Access bajo
la licencia CC BY-NC-ND (http://creativecommons.org/licenses/by-nc-nd/4.0/).

Available online: 19-03-2019 Arch Cardiol Mex. 2019;89(1):51-54 www.archivoscardiologia.com 


\section{Introduction}

For many years, the traditional treatment for valvular diseases was performed with surgical valve replacement; the decision on the type of prosthesis depends on different characteristics ${ }^{1}$. There are two types of prosthesis: mechanical and biological; biological degenerates and dysfunctions earlier with the consequent need for reoperation, and mechanical prosthesis increases the risk of valvular thrombosis, stroke, and hemorrhage due to the need of maintaining anticoagulation with an international normalized ratio within range ${ }^{1}$.

Eventually, biological prosthesis will dysfunction, and the usual technique used for handling this situation is transcatheter replacement, which represents a lower risk compared to a surgical reoperation'. In patients who have high surgical risk and biological prosthesis dysfunction, the valve-in-valve (ViV) replacement is the option procedure, using the technique of transcatheter valve aortic implantation. This technique has been carried out to a greater extent for aortic degenerated bioprosthesis; however, in tricuspid valve, the first implant reported was in $2010^{2}$.

Replacement of tricuspid valve in valvular heart disease is very rare and entails high mortality $(7-22 \%)$, in most cases, due to the multiple comorbidities and cardiac involvement of other valves. Reoperation in this patients carries a high mortality risk $(37 \%)^{3}$. In the past 2 years, there have been $>150$ cases reported of tricuspid ViV (TViV), demonstrating a substantial reduction of morbidity and mortality compared with reoperated patients ${ }^{4}$.

The aim of this article is to report the first case in the literature of implant ViVT bioprosthesis dysfunctional tricuspid made in Latin America and a description step by step to carry it out.

\section{Methodology}

Female 51-year-old with history of rheumatic heart disease 35 years ago, previously treated with mitral mechanical and tricuspid bioprosthetic valve replacement; subsequently, the patient presented functional class deterioration and in transesophageal echocardiography (TEE), a dysfunctional thrombotic tricuspid prosthetic valve was found. A surgical tricuspid replacement was performed with a $27 \mathrm{~mm}$ bioprosthesis (Carpentier-Edwards Perimount) without complication. After 3 years, the patient presented with deterioration of the functional class (NYHA-III) and TEE evidenced degenerated tricuspid bioprosthetic. It was assessed by the heart team and due to the high surgical risk and hostile chest, TViV replacement was performed.

\section{Results}

\section{Step-by-step procedure}

To determine the type and size of the bioprosthesis to be used, there are two options, one is based in ViV application (version 2.2) and the other, that could be considered more appropriate, is to determine the diameter, area, and perimeter of the previous prosthesis by computer tomography; in this case, ViV application was used and an XT Sapien valve No. 29 was determined.

Subsequently, the procedure was performed in the cath lab under general anesthesia, with orotracheal intubation and support of transesophageal echocardiogram (TEE).

Before the prosthesis release, it is required a temporal rapid passing, to perform this, we have three different options: (1) coronary sinus electrode, (2) left ventricle electrode, and (3) pacing through the support guidewire which delivers the prosthesis. For this case, the second option was selected, and the procedure is started through the left femoral arterial access with $6 \mathrm{Fr}$ introducer, advancing a multipurpose catheter (MPC) and a 6 Fr guidewire across the aortic valve, then a temporary pacing electrode was introduced in the left ventricle (Fig. 1A-C).

Another access through the right femoral venous was made, advancing an $18 \mathrm{Fr}$ introducer with a $6 \mathrm{Fr}$ pigtail catheter, toward the right ventricle (RV) and a 5 Fr MPC to the right atrium to measure the mean transvalvular tricuspid gradient at $10.7 \mathrm{mmHg}$; right ventriculography showed tricuspid regurgitation $3+/ 4+$ according to Sellers classification (Fig. 1D-F).

Through the pigtail, an extra stiff guidewire 0.032 (Teflon-tipped $\mathrm{J}$ curve) is advanced with a preformed spiral to RV; the NovaFlex ${ }^{\circledR}$ delivery system was moved toward the right atrium, and within the inferior vena cava, the assembly and alignment with the valve were performed by pulling the balloon catheter straight back at the Y-connector, then slowly rotate the fine adjustment wheel toward the operator to center the Sapien XT valve exactly between the valve alignment markers with no gap or overlap (according to the Edwards LifeScience ${ }^{\circledR}$ recommendations), then it moved forward the tricuspid valve plane, the initial alignment was confirmed with an estimated $10 \%$ of the prosthesis in the auricular side and $90 \%$ supported in the Perimount's commissure posts, which function as a frame for the Sapien XT valve and decreased the embolism risk. Starting with the release sequence (rapid pacing 180 stimuli per minute - slow insufflated of balloon - quickly insufflated to full volume - deflated balloon - stop 


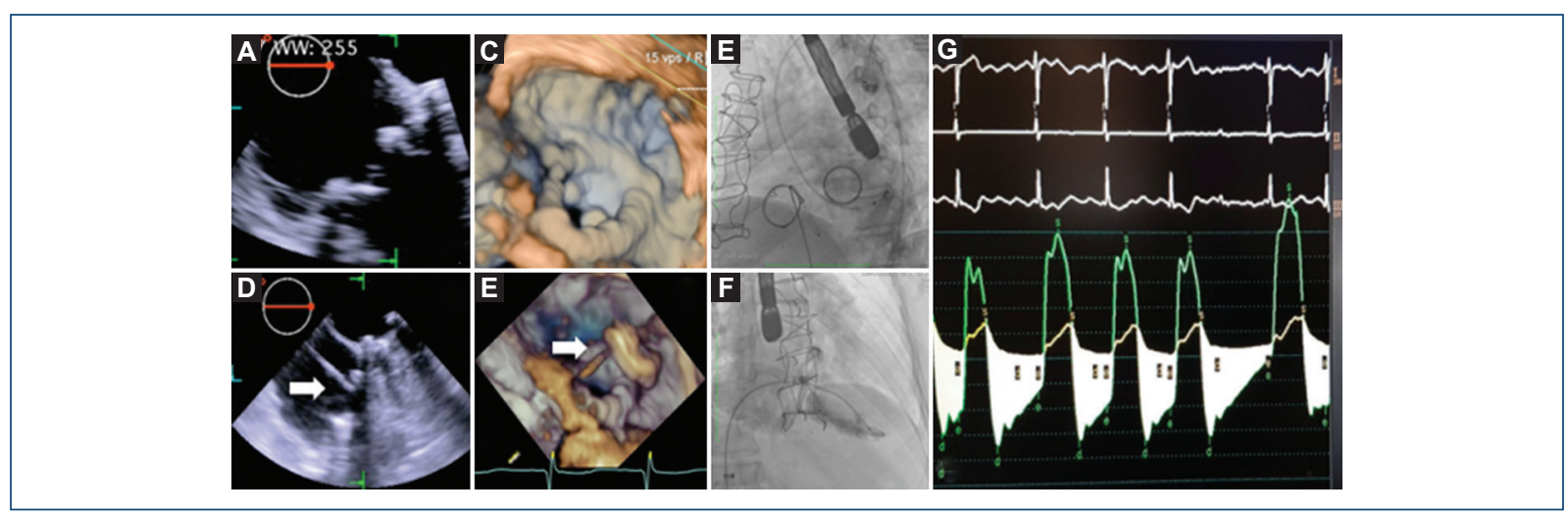

Figure 1. Pre-procedure two-dimensional (2D) (A) and three-dimensional (3D) (B) transesophageal echocardiography midesophageal $0^{\circ}$ with prosthesis dysfunction ( $\mathrm{a}$ and $\mathrm{b}$ ). Fluoroscopic left side view showing the pacemaker electrode in the left ventricle (C). Guidewire across the extra support Amplatz preformed Teflon from the right atrium through the Bioprosthesis Carpentier-Edwards Perimount (white arrow), from the transesophageal echocardiogram $0^{\circ}$ view of four cavities $2 \mathrm{D}(\mathbf{D})$ and $3 \mathrm{D}(\mathbf{E})$. Fluoroscopic right oblique anterior image with the right ventriculography showing severe tricuspid regurgitation $(\mathbf{F})$ and measurement of the mean tricuspid transvalvular gradient $(\mathbf{G})$

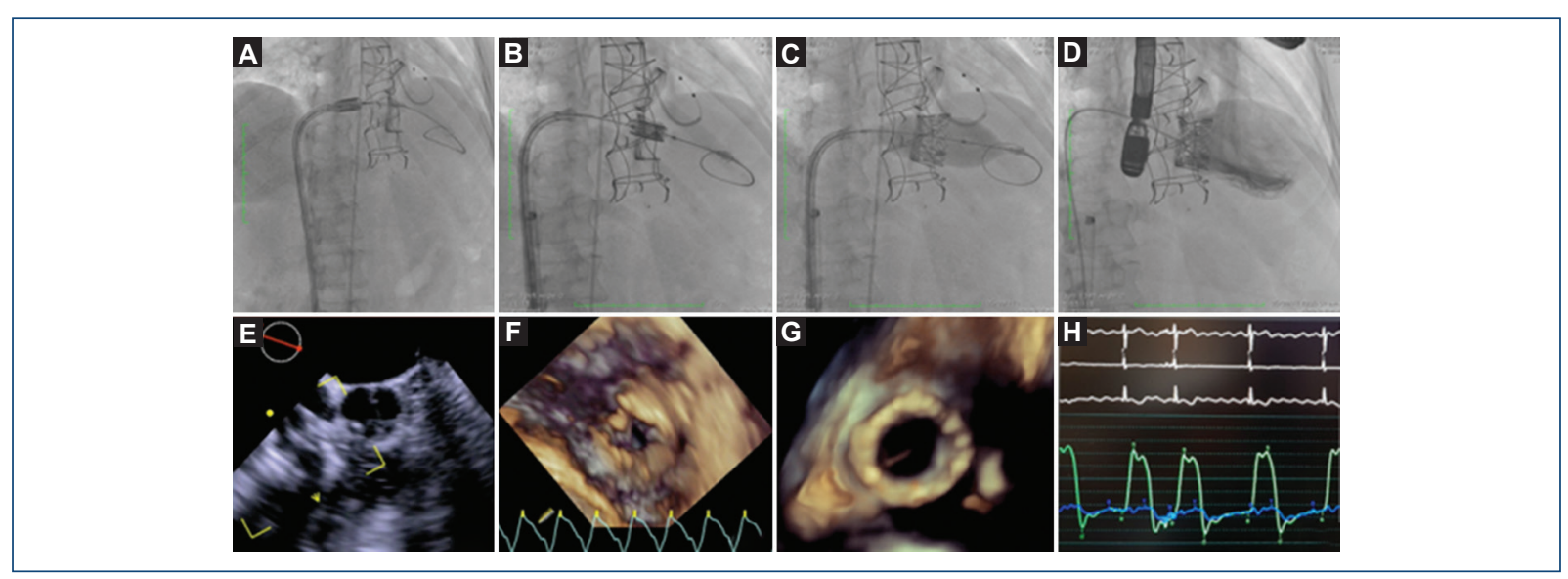

Figure 2. Sequence of the release of prosthesis: balloon crossing (A), slow balloon inflation (B), faster inflated to full volume (C). Two-dimensional transesophageal echocardiogram $19^{\circ}$ midesophageal view of inflow-outflow right ventricle with the balloon through the tricuspid valve (D). Three-dimensional (3D) echocardiography atrial view of the tricuspid valve at the time of crossing the balloon (E). Ventricular 3D view of the implanted prosthesis catheter (F). Measurement with pigtail of transvalvular mean gradient at $2 \mathrm{mmHg}(\mathbf{G})$. Right ventriculography, without evidence of TR (H)

pacing) and release the prosthesis through a balloon volume according to the valve, in this $29 \mathrm{~mm}$ Sapien $\mathrm{XT}$ valve case, a $33 \mathrm{ml}$ balloon was used (Fig. 2A-F).

After recover the release system, a pigtail catheter was moved toward RV measuring a mean transvalvular gradient of $2 \mathrm{mmHg}$ (Fig. 2G), a right ventriculography showed no evidence of tricuspid regurgitation (Fig. 2H); the $18 \mathrm{Fr}$ catheter was removed. Percutaneous closure with vascular closure device (ProGlide) of the femoral vein access site was made; pacing electrode and left femoral arterial introducer were withdrawn, then hemostasis with Angioseal $6 \mathrm{Fr}$ of the arterial access was performed. The patient was discharged $48 \mathrm{~h}$ after procedure, without complications.

\section{Discussion}

TViV technique has been reported with Edwards Sapien XT and Medtronic Melody valve using percutaneous vascular access (femoral, subclavian, or jugular) or transatrial access under direct vision ${ }^{5}$. The ViV International Registry reports 156 patients who underwent 
TViV or valve in ring, 58 of this patients were made with Sapien valve; after TViV, the tricuspid transvalvular mean gradient and/or the tricuspid regurgitation and the functional class improved ${ }^{4}$.

This case demonstrates a valve replacement primarily fluoroscope guided and supported by TEE, achieving a successful procedure, ensuring the ideal site for the implant to prevent complications, and using percutaneous vascular femoral access and a step-by-step guideline.

The reported complications are embolization of the prosthesis to the right cardiac cavities or into the pulmonary artery, followed by endocarditis and valvular dysfunction; others are third-grade blockade, phlebitis, and pseudoaneurysm of femoral artery².

TViV replacement is a safe and feasible procedure in the majority of cases, even in patients with severe symptoms and comorbilities ${ }^{4}$.

\section{Conclusion}

This case demonstrates the sequence of step-bystep fluoroscopic and echocardiographic imaging of TViV replacement.

\section{Financing}

None.

\section{Conflicts of interest}

The authors have no conflicts of interest to declare.

\section{Ethical disclosures}

Protection of human and animal subjects. The authors declare that no experiments were performed on humans or animals for this study.

Confidentiality of data. The authors declare that they have followed the protocols of their work center on the publication of patient data.

Right to privacy and informed consent. The authors declare that no patient data appear in this article.

\section{References}

1. Loyalka P, Nascimbene A, Metz B, et al. Transcatheter tricuspid valve-in-valve replacement. Tex Heart Int J. 2017;44:209-13.

2. Godart F, Baruteau A, Petit J, et al. Transcatheter tricuspid valve implantation: a multicentre French study. Arch. Cardiovasc Dis. 2014;107:583-91.

3. Panaich SS, Eleid MF. Tricuspid valve-in-valve implantation for failing bioprosthetic valves: an evolving standard of care. Ann Transl Med. 2016;4:410.

4. McElhinney DB, Cabalka AK, Aboulhosn JA, et al. Transcatheter tricuspid valve-in-valve implantation for the treatment of dysfunctional surgical bioprosthetic valves: an international, multicenter registry study. Circulation. 2016;133:1582-93.

5. Mylotte D, Lange R, Martucci G, et al. Transcatheter heart valve implantation for failing surgical bioprostheses: technical considerations and evidence for valve-in-valve procedures. Heart. 2013;99:960-7. 